\title{
Exploring the Relationship between the Canadian Government and Social Organizations and the Enlightenment of Our Country

\author{
Yihao Shi
}

\begin{abstract}
(Department of Law and Politics, School of Humanities and Social Sciences, North China Electric Power University, Baoding 071000, China)
\end{abstract}

\begin{abstract}
The relationship between government and social organization has its own development characteristics in different countries. Each different stage also presents different characteristics. The relationship between the government and the social organization of the Canadian government has undergone a series of development and evolution, and finally formed a social organization and The government is in harmony with each other. At present, the relationship between our government and social organization and the related system is not mature, in the state of exploration, the analysis on Canadian social organizations and government helps to explore the model for the social organization getting along with the government, further promoting the development and perfection of social organization.
\end{abstract}

Keywords: Social organization government; The relationship between government and social organization; Canadian government; Relationship between Canadian government and social organization

\section{探讨加拿大政府与社会组织的关系 及对我国的启示}

\author{
史益豪 \\ （华北电力大学人文与社会科学学院，法政系，河北 保定 071000）
}

摘要: 政府与社会组织的关系在不同的国家有着各自的发展特色，每个不同的阶段也呈现出不同的特点，加拿大政府有 社会组织的关系经历了一系列发展演变, 最终形成了社会组织和政府和谐相处, 互相合作的局面。目前, 我国政府与社会组 织的关系以及有关的体系并不成熟, 正处在一种摸索的状态中, 对加拿大社会组织和政府的分析有助于探讨我国社会组织和 政府相处的模式，促进我国社会组织的进一步发展和完善。

关键词: 社会组织政府；政府与社会组织的关系；加拿大政府；加拿大政府与社会组织的关系

中图分类号：TM 344.1 文献标志码：A

引言

加拿大作为一个多元文化的国度, 它具备的包容性的环境给了社会组织发展的空间, 但刚开始社会组 织并没有得到政府的重视, 它们的关系一度是非常紧张的, 随着社会组织越来越深入到政府政策的运营中 后, 加拿大的政府才意识到社会组织的重要性, 并采取一系列的措施来发展两者之间的关系, 如今, 加拿 大政府对社会组织的认可度非常高, 社会组织活动形式的多样化, 资金来源的多样化等使其有着深远的影 响力, 可以说, 社会组织对加拿大社会的发展起着不可替代的重要作用。

\section{1 加拿大加强政府与社会组织关系的背景}

\section{1 公民社会的成长}

加拿大是一个移民国家, 民族的多样化推动了社会的多样化, 而社会生活的多样化给加拿大带来了机 遇和挑战。多样性孕育着民主、自由和开放的活力, 也潜藏着分裂、动荡和冲突的危机（胡锐军, 2011）, 
在这样一个复杂的社会背景下，公民的政治认同和公民教育成为了当时的主要任务，对待公民的教育来源 于四个传统的民主形式: 自由民主、福利民主、参与式民主、多元化民主。这样的教育极大的促进了公民 意识的发展, 他们要求积极主动的投入到社会实践中去, 自主的去解决社会问题, 他们不再是被动的接受 者, 而是主动的参与者。

加拿大政治体制中, 行政权是大于立法权的, 政府拥有着主要的话语权, 这样的情况容易导致政府的 专制, 也就容易造成政府决策出现偏差的现状, 在现实中, 由于政府对社会的公共服务越来越无能为力, 以及决策偏差带来的不良后果使得公民有意无意的参与到政府决策中去。在 60 年代, 人权和其他群众运 动更是不断出现, 倡导个人自由的新左派也由此产生, 诸如 “个人的决策要比他的地位强”、“个人最大 化的参与和影响公共生活才是可能的公民生活” 的口号频频出现（胡锐军, 2011）, 在这样新潮的思想氛 围下, 公民参与政治的意识越来越明显, 以公民社会为载体的社会组织也大量产生, 在多种环境的影响下, 公民意识越来越强烈, 身为公民的自觉性大大的提高了, 公民这一群体态度的改变可以说是促进了社会组 织的发展, 也为政府与社会活动的关系转变施加了压力。

\section{2 福利国家的危机}

在 “二战” 后，加拿大逐渐形成了具备现代化性质的福利制度，对于西方国家来说，福利制度的基本 性质就是普及性, 这个制度虽然带来了一定意义上的公平, 但是政府为此要承受的高额支出, 再加上 20 世纪 30 年代发生的经济危机, 财政资金的不足就使得政府开始提高税收比例, 公民提交的税增加了, 但 是福利政策却在慢慢减少公民享受福利的范围、种类或者是质量。所以, 对于公民而言, 给政府交的税收 提高了, 他们对社会组织的捐赠就减少了, 降低了社会组织的收入。加拿大的政府曾试图缩减医疗政策的 规模, 但遭到了大多数人的反对, 并且具有很强的政治风险。因为保障基本人权、促进社会公平在加拿大 全民医疗领域体现更为明显, 生存权、健康权属于基本人权, 已经深深植根于加拿大人民心中。（潘记永, 2013）在这样的理念下, 加拿大政府是不可能对福利政策有着较大的改动, 如若没有一个好的应对方法, 那么政府就不得不面临着来自公民的压力。

西方国家在面临福利政策带来的危机时，社会组织也因政府政策遇到了危机，政府对社会组织支出的 减少大大降低了社会组织的收入, 同时, 社会组织作为政府公共责任的承担者, 其发展离不开政府的帮助, 如何有效的发展政府与社会组织的关系是当时加拿大政府的主要关注点, 为此, 加拿大政府建立了任务小 组来为社会组织服务等其他措施, 目前, 加拿大政府与社会组织的关系得到了极大的发展。

\section{2 加拿大加强政府与社会组织合作关系面临的障碍}

\section{1 政府加强对社会组织管理与社会组织自治性之间的矛盾}

社会组织对自主性有着较高的要求, 而政府却通过资源或者政策等方面来对社会组织实施控制, 在加 拿大, 政府对社会组织实施了问责制度, 这样的举措也就造成了加拿大政府和社会组织愈加紧张的关系。 和如何去平衡政府实施的问责制度和社会组织要求的自主权是缓解两者关系的重要方面。

加拿大的法律将社会组织分为两大类, 即慈善社会组织和非慈善社会组织。它们都享有免税的福利, 慈善组织除了享有免税待遇还有发放免税发票的特权。由此可见, 政府对社会组织提供了很宽松的政策支 持, 随着政府提供更多的支持, 就会要对社会组织实施更全面的问责制度。政府需要了解所投资资金的用 处, 而社会组织缺乏一套完备的体系来规范它们进行的活动, 政府的问责制度不仅仅是促进了社会组织体 
系的完善, 更是一种外在的监督。社会组织在没有监管的情况下容易发生私吞钱财, 以社会组织的名义为 个人办事情等类似的恶性事件。在不同的国家有公共丑闻缠身的社会组织激起了人们对政府部门更高的期 望值, 以至于社会组织必须对公共與论做出回应 (Salamon and Anheier 1996, 126).在这样的压力下, 社会组 织感到了恐慌, 它们不得不采取措施来进行回应, 而这样的结果就是社会组织的自主性面临着被削弱的情 况。

\section{2 政府和社会组织不恰当的合作方式}

政府和社会组织之间互补的特质应该能够很好的促进政府与社会组织的合作关系，但是合作方式的不 恰当会进一步的造成双方的紧张关系。

社会组织可能是政府的特定社会服务承担者, 以此来满足特定的社会需求, 它们也可能扮演着承担政 府某一部门或机构的特定功能, 或者是它们对政府有着特别强的依赖能力, 由于它们缺乏资金或者是需要 依赖政府的政策等相关政府的帮助才能有效的完成活动。这样的社会组织和政府之间的关系是失衡的，失 衡的关系不论是对政府还是社会组织都有着较强的消极影响。

不同的学者对两者之间的影响有着不同的解读，萨拉蒙认为社会组织会成为政府的一个代理机构并会 丧失其提供公共服务的有效性，然而，有学者认为政府能够使社会组织的政治性特征更为明显。在另一方 面, 社会组织会参与到政府制定决策中的活动中来, 由于社会组织里有着专业人才也有着一定的信息资源, 能很好的弥补政府决策的不足, 当然, 政府允许社会组织的参与主要是为了粉饰政府的决策或者让社会组 织成为公共批评的接受者, 这一种合作方式只会让社会组织成为政府的附庸者, 但是独立性较强的社会组 织可以通过这样的形式来对政府施加压力, 比如可以对政府的选举产生产生影响。通过观察社会组织和政 府的关系, 发现政府由于在经济上占据着主导地位, 所以在这段关系里处于一种主导地位, 但是从中也可 以发现对政府的弊端。萨拉蒙对此作出了风险解释，第一，政府服务的选择可能会受到在该领域的机构可 以承担特定功能的限制; 第二, 监测的成本可能限制政府对非营利机构负责的能力; 第三, 和非营利或者 是私人部门签订外包的合作关系可能会减少政府在公众里的信誉和可见度并在民意调查中影响他们公众 的支持(Salamon 1999, 358-60).

政府和社会组织的合作要在分析各自的利弊后再谨慎的做出选择，合作关系要建立在彼此互相信任的 基础上, 双方应该是平等的合作关系, 而不是发展成某一方的附庸, 只有健康的合作方式才能缓和政府与 社会组织的紧张关系。

\section{3 加拿大加强政府与社会组织关系的具体措施}

面对政府与社会组织之间日益紧张的关系，加拿大采取了一系列的措施来改善两者之间的关系。

\section{1 成立专门的部门（PAGVS）}

这个专门部门是 The Panel on Accountability and Governance in the Voluntary Sector （PAGVS）, PAGVS 的责任与义务是: 研究和评估部门的治理和问责实践; 在加拿大与志愿部门组织进行广泛的探讨; 提出如 何加强问责和治理的方法(PAGVS 1999, 1). PAGVS 是建立在强制的基础上对社会组织进行治理和问责的, 在 协商中, 社会组织部门的代表接受了 PAGVS 的治理和问责但是他们提出不能让规则和一系列的要求扼杀了 人们的精神领域, 要学会尊重社会组织丰富多彩的特性。

PAGVS 的成立是加拿大缓解政府和社会组织关系的一个重要举措, 它是政府和社会组织的一个润滑剂, 
它不仅给社会组织提供指导和建议促使社会组织能得到更好的发展, 也能恢复社会组织对政府的一些监

督，不让社会组织在两者的关系中一直处于弱势的地位。

\section{2 制定关系协议}

加拿大的联邦政府成立了一个志愿部门任务小组（VSTF）来代替 PAGVS 离开时遗留下的职位, VSTF 与 其他两个部门达成了新的关系协议, 来为政府和社会组织建立新的关系提供了新的基础, 能增强社会组织 的能力和改善社会组织的规章制度。

这份协议为政府和社会组织的关系奠定了一个新的基调, 为促进政府和社会组织的关系提供了积极性 和建设性的意见, 例如协议要求两者的关系是建立在一个尊重、信任等方面基础上的, 政府不再是发号施 令的那一方, 社会组织也不再是政府的附庸品。而且协议是有很大的影响力, 对政府和社会组织也有很强 的约束力，一旦被公开，那么政府和社会组织一定就要遵守协议中的内容。

\section{4 加拿大加强政府与社会组织关系的经验以及对我国的启示}

\section{1 经验}

加拿大政府和社会组织的关系是一个互补互助互易的关系。社会组织能够召集到一定数量的志愿人员 提供了应由政府负责的社会服务, 减轻了政府的负担, 这样也无形之中提供了大量的工作岗位, 缓解了工 作岗位短缺的现象, 从另一方面来说, 社会组织锻炼了大批志愿者, 公众从心里上就接纳和支持了社会组 织, 社会组织在公众心目中的影响力不可同日而语。尤其是近年来，社会组织对政府资金的依赖性大大的 降低了, 由于政府大幅度的削减开支, 政府对社会组织的直接拨款或者是按比例进行拨款的方式完全停止 了。现在加拿大社会组织的主要经费来源为: 政府捐赠、社会捐赠、会员会费、出版物收入、服务收入及 其他收入（黄竞跃，2001），由此可见，在资金资源方面，社会组织的独立性大大的提高了，在社会上的 影响力也有了显著的增长, 社会组织可以对政府施加一定的压力来对政府的政策作出影响。政府和社会组 织互相影响的关系才是健康以及持久的, 加拿大政府和社会组织如今的健康关系对我国发展政府和社会组 织的关系有着极强的借鉴意义。

\section{2 启示}

从加拿大政府和社会组织关系的演变进程中可以看到, 社会组织之前缺乏有效的运行体系再加上政府 问责制度的不完善导致社会组织体系很错乱的现象, 对于社会组织自身来说, 大多数的社会组织对自身糟 糕的管理是持一种厌恶的态度。加拿大政府建立的专门机构 (PAGVS) 则对社会组织提出了统一的管理标 准, 虽然对社会组织多样化的发展有一定的影响, 但是接受了统一管理标准的社会组织越来越符合主流文 化, 主流文化对社会组织发展的影响力度是较大的, 若背离了主流文化的社会组织就会遭受到大众的批判, 其发展的速度就会减缓, 它但当责任的能力也不会与它的专业知识相匹配。那么, 对于我国的社会组织来 说, 一定要顺应主流文化的趋势, 不然一旦落后就会面临着被淘汰的风险。

社会组织之间的发展并不是平衡的, 不论在哪个发展阶段都存在着分化严重的情况, 如若处理不好, 社会组织的声誉和美誉就会受到影响, 要想重新获得公众的认可将会是一件非常困难的事情。在同一个领 域里会不可避免的碰到社会资源分配的情况, 那么, 处于弱势地位的社会组织会遭遇到被分配的结果, 它 们所得到的资源是处于优势地位的社会组织进行分配的, 两种极端情况下的社会组织就会产生分歧, 小型 的社会组织就会采取措施来维护自身的利益, 一般的做法是使事情具有轰动性从而让大众知晓, 大众在知 
晓社会组织中两极分化严重的情况后就会降低对社会组织的信心以及信任, 这样的结果是极其不利于社会 组织的发展的。社会组织要想得到健康持续的发展就要平衡好每个社会组织之间的关系, 必要时刻, 政府 应该进行干预来防止组织内部两极分化的现象。

影响社会组织形象的因素有很多, 最为重要的是公众对社会组织的看法。在社会组织专业化和官僚化 的特质越来越明显的情况下, 社会组织无论如何都不能淹没公众的需求以及他们的声音。在现实生活中, 往往有些社会组织就会因为不清楚自身的定位而失去方向, 例如我国的红十字会, 红十字会如今在大众的 心目中不再是一个可以值得信赖的社会组织了, 由于 “郭美美事件” 的发生, 红十字会的声誉和美誉一落 千丈, 这个事件的连锁反映是导致了公众对社会组织整体的不信任, 目前, 我国社会组织正面临着严重的 形象危机。在加拿大, 对社会组织的要求就是不能因为专业化或者逐渐官僚化的特质而淹没了公众的需求 和声音, 社会组织对待热心公益的志愿者要始终保持一个好客的态度。社会组织是能够很好的提供公共服 务, 反映大众心声的组织, 始终与大众保持最密切的联系是必不可少的要求, 有着良好的形象才能赢得公 众更多的信任与支持。

加拿大的社会组织能得到较大的发展, 这与建立的专门机构来协助社会组织的发展是密不可分的, VSC 便是其中一个，这个机构有着稳定的资金来源并且有着一个较为宽厚的协议来指导政府和社会组织之间的 关系。在这一个关系中, 社会组织能够提高它作为一个整体的能力来让它得到关注以及需求得到人们的关 注, 尤其是政府希望社会组织承担更多的服务功能或者公众希望社会组织能够保障他们的利益以及权力的 时候。可见, 社会组织公众影响力的提升以及与政府关系的健康协调发展起到了非常重要的作用。在我国, 社会组织在与政府的关系中仍然处于弱势的地位, 社会组织的发展主要是靠自身的摸索, 缺少一个为社会 组织发展出谋划策的机构, 在这一点上, 可以向加拿大进行借鉴。

影响政府与社会组织关系的一个重要群体是公众。对于政府来说, 政府要保证公民的不配合不会让社 会组织承担过多的职能, 如果发生公众对政府办事能力的质疑转而更多的投向社会组织来表达自己的利益 诉求的事情, 政府也要进行防范。得到公众广泛支持的社会组织也可以在适当的对政府施加压力来谋求自 身利益, 但是不能以此作为筹码来对政府提出过分的要求。公众的态度对政府和社会组织的关系有着重要 的调节作用，公众对政府的支持以及对社会组织的支持能使双方建立一种持久的平衡关系。我国公众对社 会组织的了解不够深入, 能广泛得到公众支持的社会组织是极少数的, 这就在某一程度上说明了社会组织 处于弱势地位的原因。因而, 社会组织要积极的活跃在公众的视野当中, 并要让公众有一定的信服度, 这 样才能发展壮大。

加拿大政府与社会组织的关系能够得到较大的发展离不开多方的努力, 这也是一个长期的过程, 急于 求成的态度并不能让两者之间的关系得到缓和, 反而会恶化。对于我国来说, 合理的发展政府与社会组织 的关系还有很多的问题需要解决, 在这过程中需要积极的借鉴国外成功的经验来促进两者关系的发展。

\section{参考文献:}

[1]胡锐军. 加拿大多元文化格局中的政治认同及公民角色教育 [J]. 国家教育行政学院学报, 2011, 11:86-90.

[2]黄竞跃．加拿大 “非政府组织管理”情况介绍 [J]．高等教育研究, 2001, 02:56-57.

[3]潘记永. 浅析加拿大社会福利制度 $[J]$. 东岳论丛, 2013, 02:60-64.

[4]Salamon, Lester and Helmut Anheier, The emerging nonprofit sector:an overview, (Manchester: Manchester University Press, 1996) 
[5]华洁. 浅谈我国非政府组织存在的问题 [J]. 价值工程, 2010, 06：102-103.

[6]王文. 浅谈加拿大的非政府组织 $[\mathrm{A}]$. 中国物流与采购联合会. 全国省区市物流社团组织座谈会资料汇编 [C]. 中国物 流与采购联合会: $2003: 2$.

[7]王桂敏. 论我国非政府组织的作用 [D]. 吉林大学, 2004.

[8] 尹晓峰. 当代中国非政府组织的发展状况及引导 [D]. 山西大学, 2010.

[9] 肖爱民. 当代资本主义社会福利制度利弊分析 [J]. 湖南社会科学, 2005, (4).

[10]马克思恩格斯全集 $[\mathrm{M}] .678$.

[11]马克思恩格斯选集 (第 2 卷) [M]. 33.

\section{References:}

[1] Hu Ruijun. Political identity and civic role education in Canadian multicultural pattern [J]. Journal of National Academy of Education Administratult, 2011, 11: 86-90.

[2] Huang Jingyue. Introduction of "NGO Management" in Canada [J]. Higher Education Research, 2001, 02: 56-57.

[3] Pan Jianyong. Analysis on Canada's social welfare system [J]. Dongyue Papers, 2013, 02: 60-64.

[4] Salamon, Lester and Helmut Anheier, The emerging nonprofit sector: an overview, (Manchester: Manchester University Press, 1996)

[5] Hua Jie. On the problems of non-governmental organizations in China [J]. Value Engineering, 2010,06: 102-103.

[6] Wang Wen. On the Canadian non-governmental organizations [A]. China Federation of Logistics and Purchasing. National provinces and municipalities logistics community organization forum compilation [C]. China Federation of Logistics and Purchasing :, 2003: 2

[7] Wang Guimin. On the role of non-governmental organizations in China [D]. Jilin University, 2004.

[8] Yin Xiaofeng. The development of modern Chinese non-governmental organizations and guidance [D]. Shanxi University, 2010.

[9] Xiao Aimin. Analysis of the Advantages and Disadvantages of Contemporary Capitalist Social Welfare System [J]. Hunan Social Sciences, 2005, (4).

[10]The Complete Works of Marx and Engels [M] .678.

[11] Selected Works of Marx and Engels (Volume 2) [M] .33. 